\title{
МОРФОМЕТРИЧЕСКИЕ ИЗМЕНЕНИЯ СЕМЕННИКОВ И ЭПИДИДИМИСОВ КРЫС ПОСЛЕ ИНГАЛЯЦИОННОГО ВОЗДЕЙСТВИЯ НА ОРГАНИЗМ ТОЛУОЛА
}

\author{
(С) Волочина И.С.
}

\author{
Кафедра анатомии человека, оперативной хирургии и топографической анатомии \\ Луганского государственного медицинского университета, Луганск \\ E-mail: is_voloshina@mail.ru
}

\begin{abstract}
В представленной работе приведены данные о морфометрических показателях семенников и эпидидимисов половозрелых крыс после ингаляционного воздействия на организм толуола. Экспериментальное исследование выполнено на 60 белых крысах-самцах половозрелого возраста, которые подвергались ингаляционному воздействию толуола в

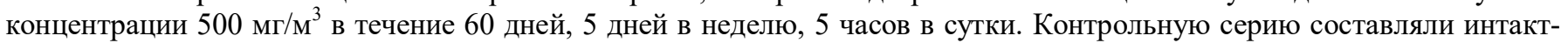
ные крысы. Данные, полученные в ходе исследования, позволяют утверждать, что в условиях ингаляционного воздействия на организм указанного химического агента отмечается снижение абсолютной массы семенников и придатков яичек, а также уменьшение их линейных размеров. Дальнейшие исследования направлены на изучение структуры органов репродуктивной системы на микроскопическом и ультрамикроскопическом уровнях и поиск препаратовкорректоров выявленных изменений.
\end{abstract}

Ключевые слова: семенники, придаток яичка, толуол, крыса.

\section{MORPHOMETRIC CHANGES IN TESTES AND EPIDIDYMIS OF RATS AFTER INHALATION EXPOSURE TO TOLUENE \\ Voloshina I.S.}

Department of Human Anatomy, Operative Surgery and Topographic Anatomy of Lugansk State Medical University, Lugansk

The study introduces the data on the morphometric parameters of testes and epididymis of mature rats after inhalation exposure to toluene. The experimental study was conducted on 60 white male rats of mature age having been exposed to toluene inhalation in a concentration of $500 \mathrm{mg} / \mathrm{m} 3$ for 60 days, 5 days a week, 5 hours a day. The control group involved intact rats. The data obtained during the investigation suggest that in effect of inhalation exposure to this chemical agent, there is a decrease in the absolute weight of the testes and epididymis, as well as a decrease in their linear dimensions. Further research is aimed at the study of the microscopic and ultramicroscopic levels of reproductive structure and search for drugs enabling to correct the changes detected.

Keywords: testis, epididymis, toluene, rat.

Репродуктивная система является одной из наиболее чувствительных систем организма, быстро реагирует на загрязнение окружающей среды, которое характеризуется длительной и малой интенсивностью воздействия неблагоприятных факторов. Независимо от их природы они вызывают нарушения функции репродуктивной системы, характер реакций которой на присутствие загрязнителей окружающей среды различных химических и физических факторов не специфичен [6]. Анализ промышленных и городских районов показал значительное процентное содержание в них ароматических углеводородов, в том числе толуола (С7H8), который представляет собой по химической структуре метилбензол [8]. Это бесцветная летучая жидкость с запахом бензола, которая может воспламеняться и взрываться в воздухе. Опасность загрязнения атмосферного воздуха метилбензолом обусловлена токсическим действием на живые организмы как непосредственно самого углеводорода, так и продуктов его трансформации (фенола и формальдегида), которые образуются в атмосфере под действием целого ряда физикохимических факторов [5]. Толуол является важным в промышленном отношении промежуточным химическим продуктом, производство которого постоянно увеличивается и достигает огромных величин [1].

Изучение токсичности толуола для человека проводилось главным образом на лицах, подвергавшихся ингаляционному воздействию в экспериментальных или производственных условиях или при намеренном употреблении в качестве наркотиков растворяющих смесей, содержащих толуол [1]. В экспериментах на животных определение влияния толуола на организм осуществляется в виде ингаляционной затравки. В связи с этим является актуальным изучение состояния половой системы крыс в условиях хронического ингаляционного воздействия на организм толуола.

Цель данного исследования заключается в выявлении морфометрических изменений семенников и придатков яичка половозрелых крыс после 
ингаляционного воздействия на организм толуола.

\section{МАТЕРИАЛЫ И МЕТОДЫ ИССЛЕДОВАНИЯ}

Экспериментальное исследование выполнено на 60 белых крысах-самцах, которые были введены в эксперимент в возрасте 12 недель с начальной массой 130-150 г. Животные были получены из вивария Луганского государственного медицинского университета. Содержание и манипуляции над животными выполнялись в соответствии с основными этическими принципами в сфере биоэтики, которые изложены в «Европейской конвенции о защите позвоночных животных, используемых для экспериментальных и других научных целей», которая была ратифицирована в 1985 году в Страсбурге [7], согласно стандарту, идентичному международному документу OECD Test № 421 «Reproduction/Developmental Toxicity Screening Test» (OECP Тест № 421 «Скрининговое исследование репродуктивной/эмбриональной токсичности») [2], согласно рекомендациям «Про правовые, законодательные и этические нормы и требования при выполнении научных морфологических исследований [4].

Крысы были разделены на контрольную (К) и экспериментальную серии (II). Контрольную серию составляли интактные крысы. Экспериментальная серия - серия II была представлена крысами, которые подвергались ингаляционному воздействию толуола в концентрации $500 \mathrm{Mг} / \mathrm{M}^{3}$ в течение 60 дней, 5 дней в неделю, 5 часов в сутки. Условия создавались с помощью специальной установки, которая состоит из затравочной камеры и камеры, в которой поддерживалась необходимая концентрация действующего вещества; датчика толуола и вспомогательного оборудования. Каждая серия животных была разделена на пять групп (по 6 крыс в каждой) в соответствии со сроками выведения животных из эксперимента на 1 , $7,15,30$ и 60 сутки после прекращения воздействия толуола.

После окончания эксперимента животных взвешивали на лабораторных весах и выводили путем декапитации под эфирным наркозом, соблюдая «Методические рекомендации по выводу лабораторных животных из эксперимента».

Внутренние органы половой системы крыс извлекали единым комплексом с окружающей жировой тканью и тщательно препарировали. Семенники и придатки яичка взвешивали на аналитических весах ВЛА-200 с точностью до 1 мг. Далее, с помощью Video Presenter SVP-5500 фотографировали полученные органы для создания обзорных фотографий, а также для дальнейшего макро- морфометричного анализа, который осуществляли с помощью оригинальной компьютерной программы «Master of Morphology, 2008» [3]. С помощью вышеупомянутой программы были определены следующие морфометрические показатели: длина и ширина яичек; общая длина, ширина головки и ширина хвоста придатка яичка.

С помощью статистических методов исследования с использованием программы «STATISTICA 6.0» определяли среднюю (Mean), среднее квадратическое отклонение вариант (SD) в каждой группе, критерий Стьюдента (t). При определении разницы между средними показателями достоверной считали статистическую погрешность менее 5\% $(\mathrm{p}<0,05)$. Коэффициент Стьюдента и уровень значимости выражали как p1 и t1 соответственно при сравнении значений групп контрольной и экспериментальной серии II.

\section{РЕЗУЛЬТАТЫ ИССЛЕДОВАНИЯ И ИХ ОБСУЖДЕНИЕ}

В результате проведенного исследования мы установили, что конечный показатель массы половозрелых крыс, которые подвергались воздействию толуола, в первые сутки после прекращения действия указанного фактора составил 222,46 г, что достоверно ниже показателя контроля соответствующей группы на $14,1 \%(\mathrm{p}=0,003)$. Прирост массы крыс в указанной группе составил 76,66 г. Средний показатель конечной массы крыс 2-й группы был зафиксирован на уровне 245,51 г, что составляет $87,37 \%(\mathrm{p}=0,043)$ от показателя соответствующей группы контрольной серии, на 60-е же сутки после прекращение действия толуола разница между показателями масс достигла 5,82\% (p=0,450) (табл. 1).

Средний показатель абсолютной массы правого яичка крыс 1-й и 4-й групп II экспериментальной серии составил соответственно 1408,70 мг и 1749,04 мг, что достоверно ниже показателей соответствующих групп контрольной серии на $10,32 \%(\mathrm{p}=0,023)$ и $5,32 \%(\mathrm{p}=0,035)$. Относительная масса в указанных группах была 633,25 и 606,81 мг/100 г массы тела животного соответственно. Абсолютная масса левого яичка крыс 1-й группы II серии оказалась достоверно ниже показателя соответствующей группы контрольной серии. Так, разница составила $10,12 \%(p=0,003)$. Крысы 4-й группы имели показатель абсолютной массы левого яичка после прекращения действия толуола на уровне 1723,34 мг, что составляет $95,02 \%(\mathrm{p}=0,042)$ от показателя соответствующей группы серии контроля (рис. 1). Относительная масса левого яичка в указанной группе составила 571,86 мг/100 г массы тела животного $(\mathrm{p}=0,766)$. 
Таблица 1

Показатели массы тела половозрелых животных контрольной серии и крыс, которые подвергались воздействию толуола

\begin{tabular}{|c|c|c|c|c|c|c|c|c|c|c|c|c|c|}
\hline \multirow[b]{2}{*}{ Серия } & \multirow[b]{2}{*}{ Группа } & \multicolumn{5}{|c|}{ Начальная масса(г) } & \multicolumn{5}{|c|}{ Конечная масса (г) } & \multicolumn{2}{|c|}{ Прирост массы } \\
\hline & & Mean & SD & $\max$ & $\min$ & $\begin{array}{l}\mathrm{t} 1 \\
\mathrm{p} 1\end{array}$ & Mean & SD & $\max$ & $\min$ & $\begin{array}{l}\mathrm{t} 1 \\
\mathrm{p} 1\end{array}$ & $\Gamma$ & $\%$ \\
\hline \multirow{5}{*}{ K } & 1 & 145,33 & 25,42 & 190,18 & 115,56 & - & 259,00 & \begin{tabular}{|l|l|}
11,67 \\
\end{tabular} & 269,10 & 238,73 & - & 113,67 & 78,21 \\
\hline & 2 & 147,18 & 6,63 & 152,92 & 135,66 & - & 281,00 & 26,32 & 305,13 & 236,90 & - & 133,82 & 90,92 \\
\hline & 3 & 144,54 & 13,54 & 156,95 & 121,86 & - & 297,00 & 40,68 & 374,52 & 259,82 & - & 152,46 & 105,48 \\
\hline & 4 & 148,91 & 20,40 & 187,78 & 130,27 & - & 311,00 & 28,61 & 337,41 & 256,54 & - & 162,09 & 108,85 \\
\hline & 5 & 146,03 & 13,43 & 158,43 & 120,46 & - & 335,00 & 34,71 & 370,15 & 274,80 & - & 188,97 & 129,40 \\
\hline \multirow{5}{*}{ II } & 1 & 145,80 & 15,11 & 161,09 & 119,60 & \begin{tabular}{|c|c}
0,04 \\
0,970
\end{tabular} & 222,46 & 19,73 & 244,25 & 187,12 & $\begin{array}{l}3,91^{*} \\
0,003\end{array}$ & 76,66 & 52,58 \\
\hline & 2 & 147,83 & 19,04 & 165,26 & 113,19 & $\begin{array}{c}0,08 \\
0,939\end{array}$ & 245,51 & 26,75 & 278,67 & 200,69 & $\begin{array}{l}2,32 * \\
0,043\end{array}$ & 97,68 & 66,08 \\
\hline & 3 & 145,80 & 6,25 & 151,76 & 134,67 & $\begin{array}{c}0,21 \\
0,841\end{array}$ & 263,88 & 10,12 & 273,09 & 248,92 & $\begin{array}{c}1,93 \\
0,082\end{array}$ & 118,09 & 81,00 \\
\hline & 4 & 150,51 & 13,35 & 165,25 & 126,60 & $\begin{array}{c}0,16 \\
0,876\end{array}$ & 288,24 & 11,69 & 305,62 & 277,13 & $\begin{array}{c}1,80 \\
0,101\end{array}$ & 137,73 & 91,51 \\
\hline & 5 & 147,24 & 16,04 & 167,13 & 120,36 & $\begin{array}{c}0,14 \\
0,890\end{array}$ & 315,50 & 49,91 & 354,94 & 222,47 & $\begin{array}{c}0,79 \\
0,450\end{array}$ & 168,26 & 114,28 \\
\hline
\end{tabular}

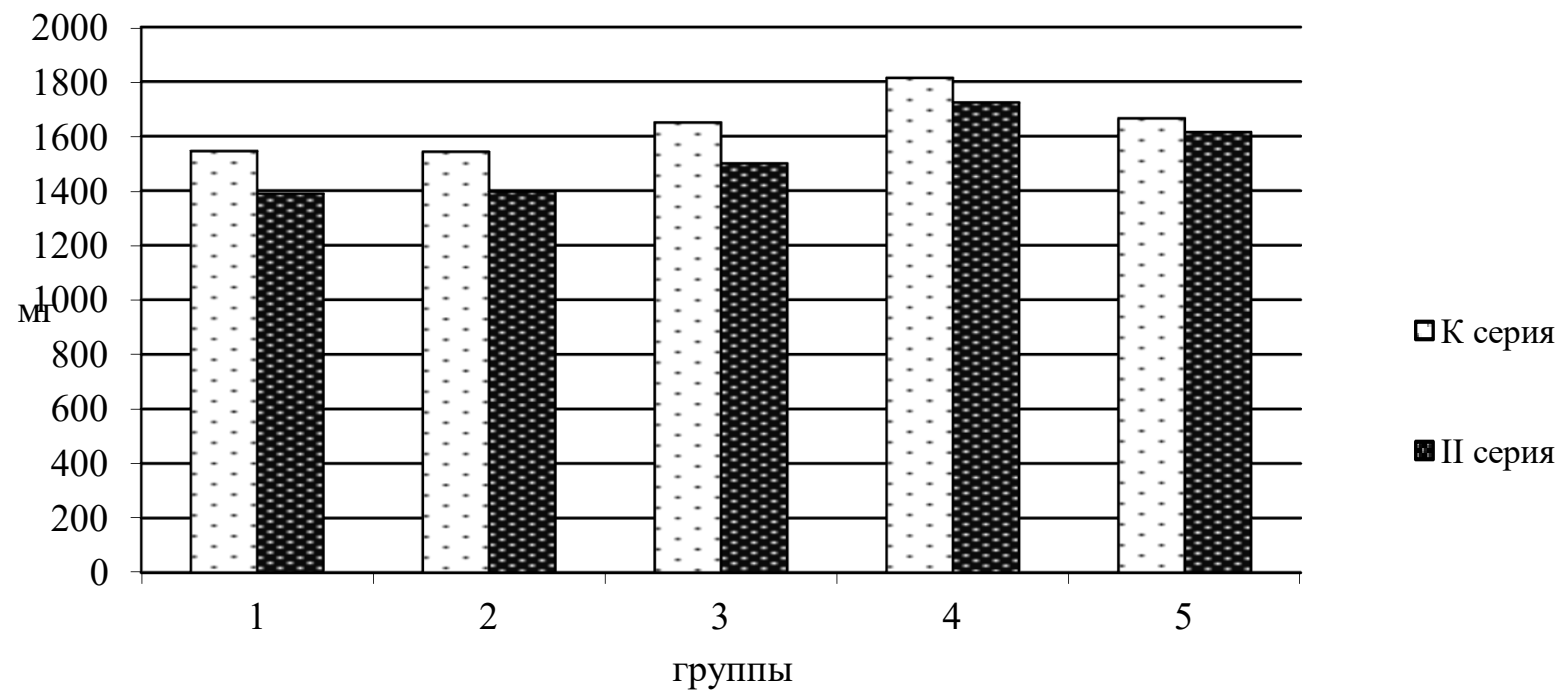

Рис. 1. Показатели абсолютной массы левого яичка половозрелых крыс.

Средний показатель длины правого яичка крыс, которые в эксперименте подвергались воздействию толуола, в первые сутки после прекращения действия указанного фактора составил 18,82 мм, что ниже показателя одноименной группы контрольной серии на $6,09 \%(\mathrm{p}=0,182)$. Максимальная длина правого яичка в указанной группе животных была зафиксирована на уровне 20,79 мм. Через 30 суток после прекращения действия толуола средний показатель длины правого яичка крыс II серии был определен на уровне 20,47 мм, что составляет $96,42 \% \quad(p=0,383) \quad$ от показателя соответствующей группы контрольной серии. Средний показатель ширины правого яичка животных II серии на 15 -е сутки после прекращения действия толуола составил 12,22 мм, что меньше показателя одноименной группы контрольной серии на $4,83 \%(\mathrm{p}=0,312)$. В ходе проведенного исследования мы установили, что средние показатели длины левого яичка крыс II серии на 1-е и 7-е сутки после прекращения действия толуола равнялись соответственно 17,86 мм и 18,06 мм, что ниже показателей одноименных групп контроля на $6,2 \%(\mathrm{p}=0,282)$ и $6,71 \% \quad(\mathrm{p}=0,289) \quad$ соответственно. Средний показатель ширины левого яичка крыс II серии в первые сутки после прекращения действия изучаемого фактора составил 9,45 мм, что составляет $\quad 91,75 \% \quad(p=0,074) \quad$ от показателя соответствующей группы контрольной серии. Минимальная ширина левого яичка животных 
1-й группы, которые в эксперименте подвергались ингаляционному воздействию толуола, была зафиксирована на уровне 8,73 мм.

При изучении показателей абсолютной массы правого придатка яичка крыс II серии мы установили, что существует достоверная разница между указанным показателем и показателем соответствующей группы контрольной серии в первые сутки после прекращения действия изучаемого фактора. Так, абсолютная масса правого придатка яичка крыс 1-й группы II серии составила 472,12 мг, а в контрольной - 530,41 мг, разница была равна 58,29 мг, что составляет $10,99 \% \quad(p=0,017) . \quad$ Средний показатель абсолютной массы левого придатка яичка половозрелых крыс 1-й и 2-й групп экспериментальной серии II был зафиксирован на уровне 457,62 мг и 499,96 мг соответственно, что ниже показателей соответствующих групп контрольной серии на $10,37 \%(\mathrm{p}=0,002)$ и $10,61 \%(\mathrm{p}=0,064)$.

Максимальная длина правого придатка яичка половозрелых крыс, которые подвергалась воздействию толуола, в первые сутки после прекращения действия указанного фактора составила 45,83 мм, средний показатель длины правого придатка яичка в указанной группе оказался на уровне 42,25 мм, что ниже показателя соответствующей группы контрольной серии на $8,81 \%$ ( $\mathrm{p}=0,170)$. Средний показатель ширины головки правого придатка яичка крыс II серии 3-й группы был зафиксирован на уровне 5,53 мм, a 4-й группы - 5,9 мм, что в целом ниже показателей соответствующих групп контрольной серии соответственно на $5,63 \%(\mathrm{p}=0,205)$ и $5,15 \%$ $(\mathrm{p}=0,375)$. Статистически достоверная разница между показателями ширины хвоста правого придатка яичка была отмечена в первой группе животных, и она составляла $7,43 \%(\mathrm{p}=0,009)$. На 1-е и 7-е сутки после прекращения действия толуола средние показатели длины левого придатка яичка крыс II серии составили соответственно 42,24 мм и 40,6 мм, что ниже показателей одноименных групп контрольной серии на $8,93 \%(\mathrm{p}=0,199)$ и $8,02 \%(\mathrm{p}=0,179)$. Средний показатель ширины головки левого эпидидимиса животных, которые подвергались воздействию толуола, на 15 -е сутки после прекращения действия ксенобиотика был равен 4,9 мм, что составляет $94,41 \% \quad(\mathrm{p}=0,242)$ от показателя соответствующей группы контрольной серии. Максимальная ширина хвоста левого придатка яичка крыс II серии 1-й группы была зафиксирована на уровне 8,01 мм, в то время как средний показатель равнялся 6,49 мм, что ниже показателя контроля на 7,29\% $(\mathrm{p}=0,173)$.

В результате проведенного исследования установлено, что в условиях хронической ингаляционной интоксикации половозрелых крыс толуолом происходят существенные изменения в органах репродуктивной системы, которые в первую очередь проявляются снижением массы семенников и придатков яичка, a также изменением линейных размеров органов в сторону уменьшения.

\section{ЛИТЕРАТУРА}

1. Витрищак С.В., Бондаренко В.В., Изоркина И.И., Гаврик С.Ю., Бондаренко М.В., Санина Е.В. Воздействие толуола на организм человека и меры профилактики // Український журнал клінічної та лабораторної медицини. - 2013. - Т. 8, № 2. C. 12-16.

2. Евразийский совет по стандартизации, метрологии и сертификации (ЕACC). Методы испытания по воздействию химической продукции на организм человека. Испытания по оценке репродуктивной/эмбриональной токсичности (скрининговый метод). - М. : Стандартинформ, 2013. $-18 \mathrm{c}$.

3. Комп'ютерна програма для морфометричних досліджень «Master of Morphology» / Овчаренко В.В., Маврич В.В. - Свід. про реєстрацію авт. права на винахід № 9604 (дата регистрации 19.03.2004).

4. Мишалов В.Д., Чайковский Ю.Б., Твердохлеб И.В. Про правовые, законодательные и этические нормы и требования при выполнении научных морфологических исследований // Морфология. 2007. - T. 1, № 2. - С. 108-115.

5. Смагулов Н.К., Крашановская Т.Р., Узбеков В.А. Гигиеническая оценка загрязнения воздуха ароматическими углеводородами с учетом процессов их трансформации в атмосфере промышленного региона // Гигиена и санитария. 1997. - № 4. - C. 12-14.

6. Хлякина О.В., Захряпина Л.В., Гулин А.В., Агаджанян Н.A. Особенности развития нарушений фертильности у мужчин репродуктивного возраста в зависимости от уровня антропотехногенной нагрузки региона проживания // Вестник ТГУ. 2010. - Т. 15. Вып. 5. - С. 1531-1534.

7. European convention for the protection of vertebrate animals used for experim. and other scientific purposes. Coun. of Europe (Strasbourg, 1986). Strasbourg, 1986. $-53 \mathrm{p}$.

8. Yamamoto K., Fukushima M., Kakutani N., Kuroda K. Volatile organic compounds in urban rivers and their estuaries in Osaka, Japan // Environ. Pollut. - 1997. Vol. 95, N 1. - P. 135-143. 